\title{
COMPARATIVE STUDY OF WEAR RESISTANCE OF THE COMPOSITE WITH MICROHYBRID STRUCTURE AND NANOCOMPOSITE
}

\author{
Daniel PIENIAK*, Agata WALCZAK*, Agata M. NIEWCZAS*
}

\begin{abstract}
*Department of Applied Mechanics, Main School of Fire Services, 52/54 J. Słowackiego St., 01-629 Warszawa, Poland *Department of Conservative Dentistry with Endodontics, Medical University of Lublin, 7 Karmelicka St., 20-081 Lublin, Poland
\end{abstract}

dpieniak@sgsp.edu.pl, awalczak@sgsp.edu.pl, agata.niewczas@umlub.pl

received 25 July 2015, revised 7 December 2016, accepted 9 December 2016

\begin{abstract}
The aim of the study was to compare microhardness and wear resistance of ceramic-polymer composites with micro and nanohybrid structure. For the studies commercial composites were used, containing filler particles of the same type but different sizes, nanosized (Filtek Ultimate) and micro-sized (Filtek Z250) composites. Tribological testing was conducted using ball-on-disc micro-tribometer. Vickers testing method was applied for microhardness studies with the use of Futertech FM 700 device. It has been demonstrated that the wear of Filtek Ultimate is almost twice lower in comparison to wear of Filtek Z250 composite. It has been concluded that the use of filler nanoparticles significantly increased wear resistance of the material. Additionally, lack of correlation between material microhardness and wear resistance has been demonstrated.
\end{abstract}

Key words: Wear Resistance, Dental Composites, Microhardness

\section{INTRODUCTION}

In conservative dentistry ceramic-polymer composites are most commonly used. It applies not only to the front teeth, but also to the side teeth - molars and premolars. The ceramicpolymer composites have suitable physical - mechanical properties to oral cavity conditions (Canche-Escamilla et al., 2014). They maintain aesthetic appearance similar to the appearance of the natural tooth tissues for a long operating time. Due to clinical reasons they should also ensure long life of the fillings.

Dental composites consist of a matrix (organic phase-resin) and filler (inorganic phase). The mechanical and tribological properties of dental composites are determined by many parameters such as: size, shape, content and distribution of filler particles in resin matrix (Wang et al., 2015). Commonly used fillers are silica fillers, glass and quartz. However, constantly new materials are being developed, which among other things would increase abrasive wear resistance of the fillings (Hambire and Tripathi, 2013). Size of the particles of inorganic phase in the modern dental composites is above $0.04 \mu \mathrm{m}$ for microfillers and above $0.005 \mu \mathrm{m}$ for nanofillers (Schmalz, 2009). The fillers are applied in a form of agglomerates (clusters) or dispersed form. It is believed that the use of filler particles in nano-sized enhance physical and mechanical properties of ceramic-polymer composites (Wang et al., 2015). The quantity of filler in the matrix depends on the type of the composite. Hybrid composites have the highest ratio of inorganic to organic phase, for which the content of the filler ranges from 60 up to 70 percent of the composite volume (\% volume) or from 70 up to 85 percent of the composite mass (\% weight).

An initial stage of classification studies in case of development of the new dental composites are in vitro studies, conducted in the laboratory conditions using material specimens. In vitro studies are carried out as preliminary studies. It decreases the time of in vivo studies and reduces the number of clinical trials (Ramalho and Antunes, 2005). One of the most important preclinical studies are studies of the mechanical properties of the surface, including hardness and abrasive wear resistance. It refers particularly to increase of wear resistance of the fillings, with reduction of the wear of opposing teeth (contact teeth). Surface damages may act as traps for particles during chewing process. They accumulate food waste and dental plaque. As a result of the described phenomena, stains may appear on the filling surface, deteriorating aesthetic appearance. Additionally, a biocompatibility of the fillings decreases (Palaniappan et al., 2013).

Wear of the composite filling in the clinical conditions is a result of the opposing teeth contact, food consumption, teeth brushing and illnesses e.g. bruxism. The wear is a sum of phenomenon occurring in the operating conditions, thus abrasive wear and adhesive effect between two mating surfaces, as well as fatigue of the surface layer of the material and corrosive effects (Mair et al., 1996). Especially important types of teeth wear are abrasion and attrition (Palaniappan et al., 2013). The abrasive wear occurs by means of the following three bodies, wearing friction surfaces of opposing teeth and foreign particles between them. In case of composite fillings the abrasive wear appears as abrasion of the soft polymer matrix exposing filler particles (Lambrecht et al., 2006). The attrition is the effect of wear caused by the direct contact of the opposing teeth surfaces, thus the result of interaction of two bodies. During mating of two rough surfaces the microroughness contact occurs. If both body surfaces are hard and brittle at the same time, thus as a result of microroughness contact they deform and fracture after exceeding a critical stress value. In case when the surface of one body has a higher hardness than the opposing surface, it can cause a fast wear by microcutting (Mair, 2000). 
Improvement of resistance to wear must be associated with relevant parameters of resistance to movement (friction coefficient). As stated in the publication (Kleczkowska and Bieliński, 2007) too large values of frictions coefficient may lead to premature wear of filling, while too small - to less efficient in crushing food. From authors observation results that the value of composites frictions coefficient in a liquid or suspension environment is within a scope from 0.2 up to 0.45 .

It is believed that the level of composite wear depends on the size and content of the filler particles in the structure of the composite and the filler adhesion to the resin matrix (Turssi et al. 2007). If the sizes of filler particles and space between them are smaller than distortions and deformations caused by the contact of two bodies, material behaves almost as a homogeneous one, and its wear is similar to resinous matrix wear. In case when filler particles and size of deformation are similar or filler particles are larger, the material behaves as a heterogeneous one, and the wear is lower than resinous base wear (Kleczkowska and Bieliński, 2007). The wear resistance of ceramic-polymer composites can be also explained through 'protection hypothesis'. The polymer is less wear resistance than filler particles so wear of composites depends from the resin spacing between the particles (Ferracane and Palin, 2013). High quantities of filler in the matrix and small size of particles have an impact on the improvement of tribological properties of composites surface under condition of good dispersion in the material.

\section{MATERIAL AND STUDY METHOD}

Two commercial ceramic-polymer composites based on methacrylate compounds Filtek Z250 and Filtek Ultimate were studied. Studied composites contain filler particles of the same type but different sizes (Fig. 1, Fig. 2). Detailed data concerning materials are presented in Tab. 1.

Tab. 1. List of the studied materials (Thomaidis et al., 2013)

\begin{tabular}{|c|c|c|c|c|}
\hline Material & Manufacture & Type & $\begin{array}{c}\text { Type and size } \\
\text { of filler } \\
\text { particles }\end{array}$ & $\begin{array}{c}\text { Filler } \\
\text { particles } \\
\text { content } \\
\text { (vol.\%) }\end{array}$ \\
\hline Filtek & 3 M ESPE & $\begin{array}{c}\text { Micro- } \\
\text { hybrid }\end{array}$ & $\begin{array}{c}\text { SiO2/ZrO2 } \\
0.01-3.5 \mu \mathrm{m}\end{array}$ & 60 \\
\hline Z250 & 3M ESPE & $\begin{array}{c}\text { Nanocomp } \\
\text { osite }\end{array}$ & $\begin{array}{c}\text { ZiO2 } 20 \mathrm{~nm}, \\
\text { ZrO2 4-11 nm, } \\
0.6-20 \mu \mathrm{m} \\
\text { clusters }\end{array}$ & 63.3 \\
Ultimate & & \multicolumn{2}{|c}{} \\
\hline
\end{tabular}

Specimens for microhardness studies were made in a disc shape according to ISO 4049 standard. Samples were cured with light emitting diode (LED) curing light for 40 seconds.

The microhardness study was conducted by Vickers method using Futertech FM 700 device with the load of $50 \mathrm{~g}$, while indenter's penetration time was set to 20 seconds. Measuring coordinates were set in order to possibly include the whole specimen surface, they were identical for all specimens. The study was carried out on 20 samples on the light exposed (LC) and nonexposed surface (NLC).

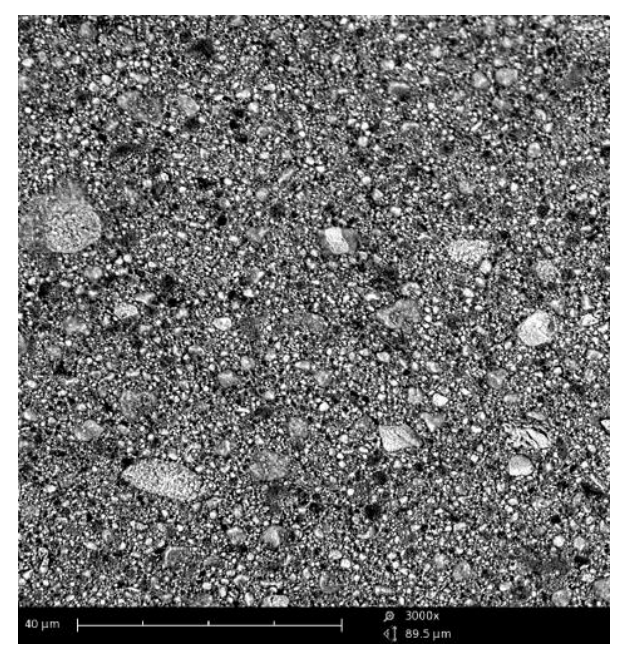

Fig. 1. SEM microstructure of Filtek Z250 composite; zoom 3000x

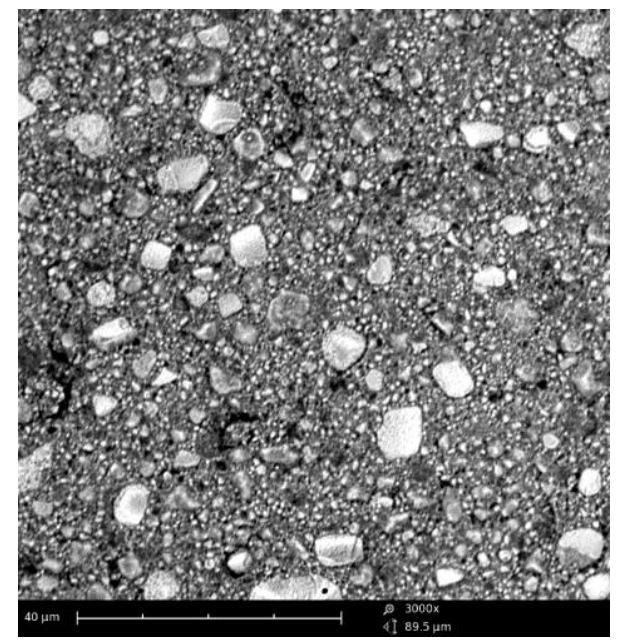

Fig. 2. SEM microstructure of Filtek Ultimate composite; zoom 3000x

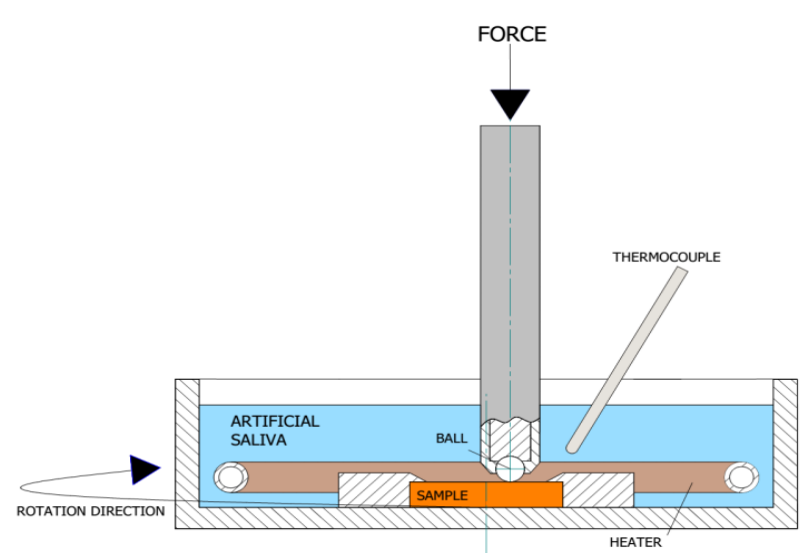

Fig. 3. Schematic diagram of wear test apparatus

Wear resistance study was conducted by means of microtribometer (CSM Instruments SA Switzerland) with the ball-on-disc method. Spherical counter specimens were applied with a diameter of $6 \mathrm{~mm}$, made of trioxide aluminum (Al2O3). During the whole period of examination the specimens were immersed in artificial saliva in order to simulate conditions in the oral cavity. A load during the testing was fixed to $5 \mathrm{~N}$. Testing speed was $60 \mathrm{rpm}$ and a sliding distance was $100 \mathrm{~m}$. The studies of wear geometry were performed by means of surface profiler - Veeco Dektak 150 . Wear resistance study was conducted on 8 samples on the light ex- 
posed surface (LC). Fig. 3 shows a schematic configuration of the test machine.

\section{STUDY RESULTS AND DISCUSSIONS}

Results of microhardness studies of composites are presented in Tab. 2. Both exposed (LC) and non-exposed (NLC) surfaces were taken into consideration. Descriptive statistics of the study results include the following: average value, minimum and maximum value, results dispersion and standard deviation.

Tab. 2. Microhardness measurement results

\begin{tabular}{|c|c|c|c|c|c|c|}
\hline \multirow[t]{2}{*}{ Material } & \multirow{2}{*}{$\begin{array}{l}\text { Surfa } \\
\text { ce }\end{array}$} & $\begin{array}{c}\text { Aver } \\
\text { age }\end{array}$ & Min & $\operatorname{Max}$ & $\begin{array}{l}\text { Dispers } \\
\text { ion }\end{array}$ & St. Dev. \\
\hline & & \multicolumn{5}{|c|}{$[\mathrm{HV}]$} \\
\hline $\begin{array}{l}\text { Filtek } \\
\text { Z250 }\end{array}$ & LC & 72.78 & 59.53 & 83.05 & 23.52 & 3.790 \\
\hline $\begin{array}{c}\text { Filtek } \\
\text { Ultimate }\end{array}$ & LC & 72.99 & 63.98 & 80.19 & 16.21 & 3.927 \\
\hline $\begin{array}{l}\text { Filtek } \\
\text { Z250 } \\
\end{array}$ & NLC & 75.24 & 65.66 & 82.37 & 16.71 & 3.490 \\
\hline $\begin{array}{c}\text { Filtek } \\
\text { Ultimate }\end{array}$ & NLC & 71.56 & 64.89 & 78.10 & 13.21 & 2.743 \\
\hline
\end{tabular}

LC - exposed side

NLC - non-exposed side

It has been observed that microhardness of Z250 composite and Ultimate composite was similar. No significant differences in average values between LC and NLC have been demonstrated. It may be explained by the same composites manufacturer.

The graphical interpretation of friction coefficient vs. distance has been illustrated in Fig. 4. The curves of friction coefficient vs. distance of studied materials were similar.

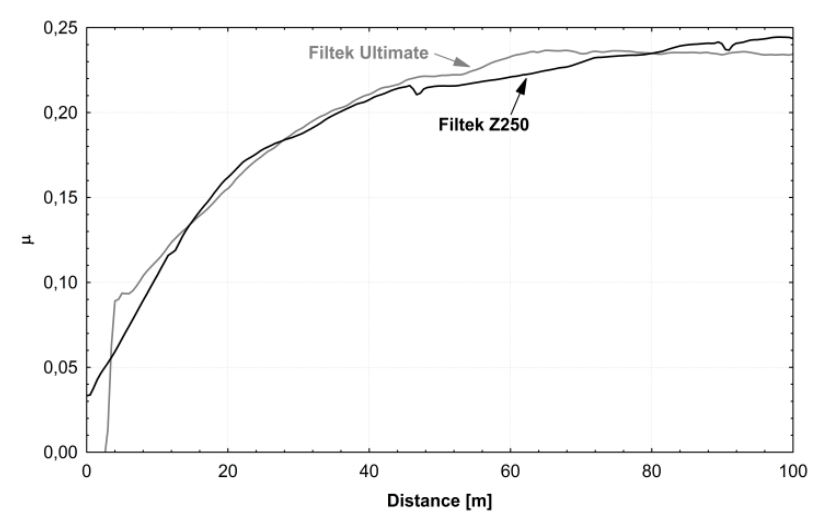

Fig. 4. The curve illustrating changes of friction coefficient vs. distance at the load of $5 \mathrm{~N}$

Wear study results are presented in Tab. 3. Descriptive statistics as in case of microhardness have been marked out, and average wear coefficient K. Additionally, the typical wear profiles of composites Filtek Z250 and Filtek Ultimate are shown in Fig. 5.

The wear resistance of Filtek Ultimate composite proved to be significantly higher than the wear resistance of Filtek Z250 composite. The maximum wear value of Filtek Ultimate was $363 \times 10^{5}$ $\mu \mathrm{m}^{3}$ and it was lower than the average wear value of Z250 composite. The wear results can be explained by the size of filler particles. Some authors claim that composites containing smaller filler particles showed greater wear resistance compared with composites with larger filler particles (Souza et al., 2016). Other provides studies indicated that filler content influences wear resistance (Wang et al., 2003). Although the similar wear mechanisms, it is difficult to compare results obtained with various methods (Heintze at el., 2005).

Tab. 3. Results of dental composites wear

\begin{tabular}{|c|c|c|c|c|c|c|}
\hline \multirow[t]{2}{*}{ Material } & $\begin{array}{c}\text { Avera } \\
\text { ge }\end{array}$ & Min & Max & $\begin{array}{c}\text { Dispers } \\
\text { ion }\end{array}$ & $\begin{array}{c}\text { St. } \\
\text { Dev. }\end{array}$ & \multirow{2}{*}{$\begin{array}{c}\text { Average } \\
\text { wear coeff. } \\
\mathrm{K} \\
{\left[\mathrm{m}^{3} \mathrm{~F}^{-1} \mathrm{~m}^{-1}\right]}\end{array}$} \\
\hline & \multicolumn{5}{|c|}{$10^{5} \mu \mathrm{m}^{3}$} & \\
\hline $\begin{array}{l}\text { Filtek } \\
\text { Z250 }\end{array}$ & 412 & 245 & 596 & 351 & 90 & $8.23 \times 10^{-14}$ \\
\hline $\begin{array}{c}\text { Filtek } \\
\text { Ultimate }\end{array}$ & 227 & 124 & 363 & 239 & 76 & $4.54 \times 10^{-14}$ \\
\hline
\end{tabular}

Based on the wear studies, the wear coefficient $\mathrm{K}$, including loading and sliding distance was determined. The coefficient for Filtek Z250 was $8.23 \times 10^{-14}\left[\mathrm{~m}^{3} \mathrm{~F}^{-1} \mathrm{~m}^{-1}\right]$ and for Ultimate it was $4.54 \times 10^{-14}\left[\mathrm{~m}^{3} \mathrm{~F}^{-1} \mathrm{~m}^{-1}\right]$.

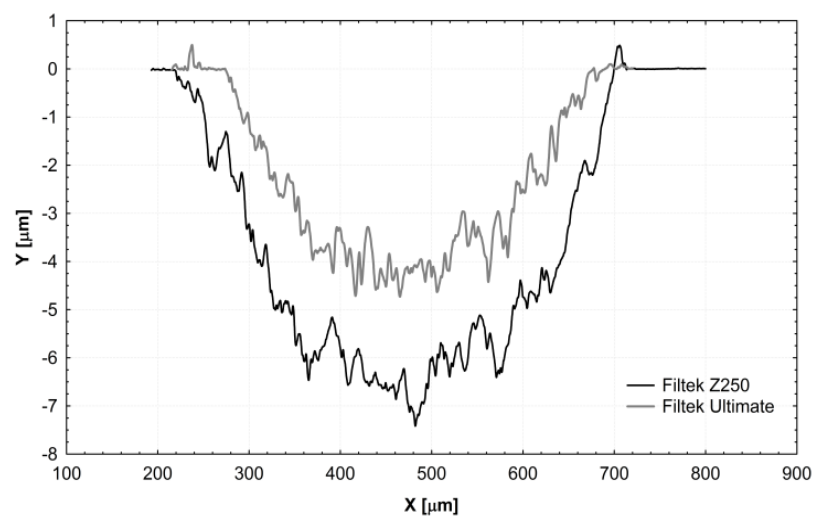

Fig. 5. Typical wear profiles

Figs. 6 and 7 show microscopic images of the wear track of composites Z250 and Ultimate. In figure 6 parallel furrows can be seen. In Fig. 7 visible microcracks propagation directions at the edges of furrows can be noticed. Branching of these microcracks and their re-connection results in separation of individual material particles in the form of scale. This way separated particle is detached from the composite surface.

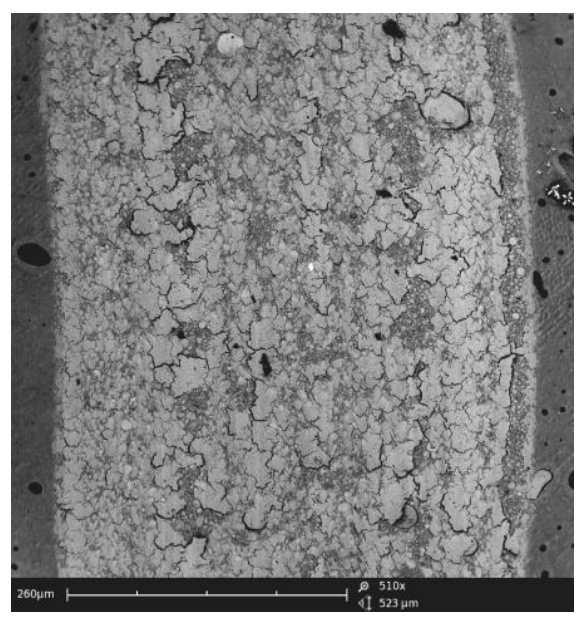

Fig. 6. Wear track of Filtek Z250 composite; zoom 510x 


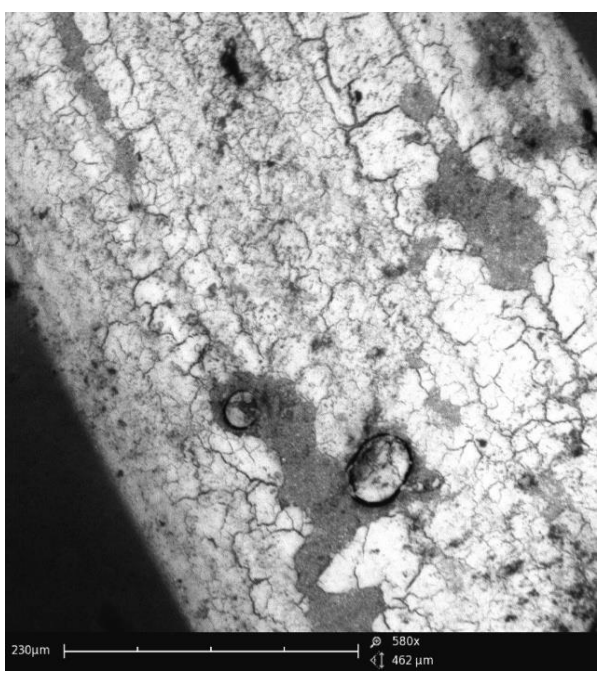

Fig. 7. Wear track of Filtek Ultimate composite; zoom 580x

\section{CONCLUSION}

In the presented studies similar values of microhardness for both composites have been obtained. It is known from the literature that there is a correlation between composite microhardness and polymerization shrinkage value. Microhardness study can be also used for the assessment of the local photopolymerization gradient, inhomogeneity of composite properties in the area of polymerization lamp light impact.

In the conducted studies a significantly higher adhesive wear of Filtek Z250 composite comparing to Filtek Ultimate has been demonstrated. The difference in wear could be a result of different composite structure. Nanoparticles content in the structure of the surface layer of Ultimate composite strengthens and unifies its structure. SEM images showed only insignificant local material gaps, while in case of Filtek Z250 material wear traces had linear shape.

It can be concluded from the literature, that the wear of composites depends mainly on the content of the filler in the matrix and size of the filler particles (Finaly et al., 2013; Turssi et al., 2007; Wang et al., 2013). In the conducted studies despite of similar filler content in Z250 and Ultimate composites, the latter one was characterized by higher wear resistance due to smaller size of filler particles (Tab. 1). The dispersion of filler in Ultimate composite was better; material was more homogeneous, with smaller space between the particles, which resulted in lower wear, most probably due to better load transfer between matrix and the filler.

\section{REFERENCES}

1. Canche-Escamilla G., Duarte-Aranda S., Toledano M. (2014), Synthesis and characterization of hybrid silica/PMMA nanoparticles and their use as filler in dental composites, Materials Science and Engineering C: Materials for Biological Applications, 42, 161-167.

2. Ferracane J.L., Palin W.M. (2013), Effects of particulate filler systems on the properties and performance of dental polymer composites, in Vallittu P. editor, Non-Metallic Biomaterials for Tooth Repair and Replacement, Woodhead Publishing, Cambridge.
3. Finlay N., Hahnel S., Dowling A.H., Fleming G.J.P. (2013), The in vitro wear behavior of experimental resin-based composites derived from a commercial formulation, Dental Matererials, 29 , 365-374.

4. Hambire U.V., Tripathi V.K. (2013), Optimization of compressive strength in Zirconia nanoclusters of the Bis-GMA and TEGDMA based dental composites, Procedia Engineering, 51, 494-500.

5. Heintze S.D., Zappini G., Rousson V. (2005), Wear of ten dental restorative materials in five wear simulators-Results of a round robin test, Dental Materials, 21, 304-317.

6. Kleczewska J., Bieliński D.M. (2007), Friction and wear of resinbased dental materials, Archives of Civil and Mechanical Engineering, 4, 87-96.

7. Lambrecht P., Debels E., Van Landuyt K., Peumans M., Van Meerbeek B. (2006), How to simulate wear? Overview of existing methods, Dental Materials, 22, 693-701.

8. Mair L.H. (2000), Wear in the mouth: the tribological dimension, in Addy M., et al., editors, Tooth wear and sensitivity. Clinical advances in restorative dentistry, Martin Dunitz Ltd., London.

9. Mair L.H., Stolarski T.A., Vowles R.W. Lloyd C.H. (1996), Wear: mechanisms, manifestations and measurement. Report of a workshop, Journal of Dentistry, 24, 141-148.

10. Palaniappan S., Celis J.P., Meerbeek B., Peumans M., Lambrechts P. (2013), Correlating in vitro scratch test with in vivo contact free occlusal area wear of contemporary dental composites, Dental Materials, 29, 259-268.

11. Palaniappan S., Peumans M., van Meerbeek B., Lambrechts $P$. (2013), Wear prediction in dental composites in Yan Y. editor, BioTribocorrosion in Biomaterials and Medical Implants, Woodhead Publishing, Cambridge.

12. Ramalho A., Antunes P.V. (2005), Reciprocating wear test of dental composites: effect on the antagonist. Wear, 259, 1005-1011.

13. Schmalz G. (2009), Resin-Based Composites in Schmalz G. and Arenholt-Bindslev D. editors, Biocompatibility of Dental Materials, Springer, Berlin Heidelberg.

14. Souza J.C.M., Bentes A.C., Reis K., Gavinha S., Buciumeanu M., Henriques B., Silva F., Gomes J.R. (2016), Abrasive and sliding wear of resin composites for dental restorations, Tribology International 102, 154-160.

15. Thomaidis S., Kakaboura A., Mueller W.D., Zinelis S. (2013) Mechanical properties of contemporary composite resins and their interrelations, Dental Materials, 29, 132-141.

16. Turssi C.P. Ferracane J.L., Vogel K. (2005), Filler features and their effects on wear and degree of conversion of particulate dental resin composites, Biomaterials, 26, 4932-4937.

17. Turssi C.P., Faraoni-Romano J.J., Menezes M., Serra M.C. (2007), Comparative study of the wear behavior of composites for posterior restorations, Journal of Materials Science: Materials in Medicine, 18, 143-147.

18. Wang L., D’Alpino P.H., Lopes L., Pereira J. (2003), Mechanical properties of dental restorative materials: relative contribution of laboratory tests, Journal of Applied Oral Science, 11, 162-7.

19. Wang R., Bao S., Liu F., Jiang X., Zhang Q., Sun B., Zhu M. (2013), Wear behavior of light-cured resin composites with bimodal silica nanostructures as fillers, Materials Science and Engineering $C$ : Materials for Biological Applications, 33, 4759-4766.

20. Wang R., Zhang M., Liu F., Bao S., Wu T., Jiang X., Zhang Q., Zhu M. (2015), Investigation on the physical-mechanical properties of dental resin composites reinforced with novel bimodal silica nanostructures, Materials Science and Engineering C: Materials for Biological Applications, 50, 266-273. 